\title{
The role of drug-coated balloons in endovascular interventions
}

\author{
Anita Miljas*, \\ Ivan Šakić, \\ Kristina Pavlović \\ Dubrovnik General Hospital,
} Dubrovnik, Croatia

\author{
KEYWORDS: drug coated balloon, endovascular interventions, in stent restenosis \\ CITATION: Cardiol Croat. 2020;15(3-4):68. | https://doi.org/10.15836/ccar2020.68 \\ *ADDRESS FOR CORRESPONDENCE: Anita Miljas, OB Dubrovnik, Roka Mišetića 2, HR-20000 Dubrovnik, Croatia. / \\ Phone: +385-98-1945-948 / E-mail: anita.miljas1@gmail.com
}

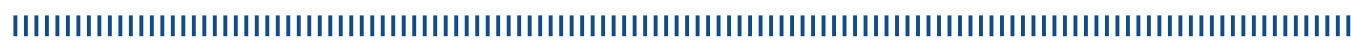

The drug coated balloons are evolution in treatment of clotted blood vessels. The era of interventional endovascular medicine began with balloon dilatation, further progress represented bare metal stents and after that drug eluting stents. In the last few years, interventional cardiology recognized the need for further evolution in treating clotted arteries. ${ }^{1}$ The concept of DCB is distribution of cytostatic drug (most commonly Paclitaxel) locally through a balloon, which is blocking uncontrolled hyperplasia of the endothelium, most common cause of restenotic lesions. This is done to prevent implanting a permanent metal, and to shorten the usage of antiaggregation therapy. The main components of DCB are balloon drug and drug carrier. Drug carrier is very important in technical concept of successfully designed DCB. DCB is usually used as conventional balloon except avoiding hand contact with the surface of the balloon is necessary because it can damage the drug. The targeted drug delivery needs to be quick because the drug releases its substance at the moment when its entries in blood flow. Ideal drug delivery for coronary intervention to the vessel lesion is 60 seconds (time from entering in blood flow till finishing inflating the balloon). Indications for DCB usage in coronary interventions are in stent restenosis, coronary narrow lesions. DCB has wide usage in interventions of peripheral arteries. It's more common usage of DCB in "de novo" coronary artery lesions after adequate preparation of the lesion with various methods (scoring balloons, cutting balloons, NC balloons). In now days DCB are unavoidable cardiac catheterization laboratory tool and whose usage is on the rise. For further expansion of indications and growing number of interventions additional study evaluations needs to be done.
RECEIVED:

February 19, 2020

ACCEPTED:

February 22, 2020

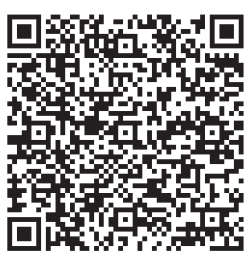

$\square$ Cardiologia Croatica 2020;15(3-4):68

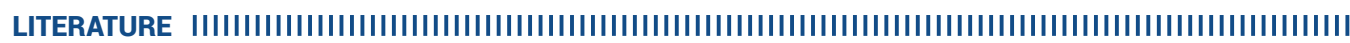

1. Ibanez B, James S, Agewall S, Antunes MJ, Bucciarelli-Ducci C, Bueno H, et al; ESC Scientific Document Group. 2017 ESC Guidelines for the management of acute myocardial infarction in patients presenting with ST-segment elevation: The Task Force for the management of acute myocardial infarction in patients presenting with ST-segment elevation of the European Society of Cardiology (ESC). Eur Heart J. 2018 Jan 7:39(2):119-177. https://doi.org/10.1093/eurheartj/ehx393 